\title{
BMJ Open Local anaesthetics combined with vasoconstrictors in patients with cardiovascular disease undergoing dental procedures: systematic review and meta-analysis
}

Caio Chaves Guimaraes (D) , ${ }^{1}$ Luciane Cruz Lopes (1) ,2 Cristiane de Cássia Bergamaschi (10) ,2 Juliana Cama Ramacciato, ${ }^{3}$ Marcus Tolentino Silva (10 , ${ }^{2}$ Jimmy de Oliveira Araújo, ${ }^{1}$ Natalia Karol de Andrade, ${ }^{1}$ Rogério Heládio Lopes Motta (1) ${ }^{3}$

To cite: Guimaraes CC, Lopes LC, Bergamaschi CdC, et al. Local anaesthetics combined with vasoconstrictors in patients with cardiovascular disease undergoing dental procedures: systematic review and meta-analysis. BMJ Open 2021;11:e044357. doi:10.1136/ bmjopen-2020-044357

- Prepublication history and additional supplemental material for this paper are available online. To view these files, please visit the journal online. To view these files, please visit the journal online (http://dx.doi. org/10.1136/bmjopen-2020044357).

Received 21 September 2020 Accepted 15 June 2021

Check for updates

(c) Author(s) (or their employer(s)) 2021. Re-use permitted under CC BY-NC. No commercial re-use. See rights and permissions. Published by BMJ.

For numbered affiliations see end of article.

Correspondence to Caio Chaves Guimaraes; drcaio_cg@hotmail.com

\section{ABSTRACT}

Objectives There is a lack of evidence about the use of local anaesthetics (LAs) in patients with cardiovascular diseases (CVD) in dental procedures. Thus, this study evaluated the safety of using LA with vasoconstrictor to determine the risk of cardiovascular events in patients with CVD.

Design Systematic review and meta-analysis.

Methods We have searched in Cochrane Central Register of Controlled Trials (CENTRAL), MEDLINE (via Ovid), EMBASE (via Ovid), Healthstar (via Ovid), CINAHL, Web of Science and ClinicalTrials.gov for randomised controlled trials (RCTs) up to January 2020. We have included RCTs involving adults with CVD within two groups: intervention group with LA with vasoconstrictor and control group with LA without vasoconstrictor. The primary outcomes assessed were death, mortality by a specific cause, stroke, acute myocardial infarction, hospitalisation, pain, bleeding and arrhythmias. The secondary outcomes were ST segment depression, anxiety, adverse effects and changes in haemodynamic parameters. The data were pooled using random effects meta-analyses and the confidence in the estimates was verified using the Grading of Recommendations Assessment, Development and Evaluation (GRADE).

Results Ten RCTs ( $n=478$ participants) were included. Most of them had a high risk of bias. There were more cases of pain and bleeding in groups without vasoconstrictor. Meta-analysis demonstrated a decrease in the systolic blood pressure with the use of LA with vasoconstrictor (standard mean difference $-0.95,95 \% \mathrm{Cl}$ -1.35 to -0.55 ) after procedure. Overall, for the other outcomes assessed there was no statistical difference. The quality of evidence was considered low according to the GRADE profile.

Conclusions The results suggest that the use of LA with vasoconstrictors (epinephrine in low doses) is safe in patients with some types of CVD. However, the low quality of evidence demonstrated that literature needs further studies in order to confirm these results.

Protocol registration PROSPERO (CRD42016045421).
Strengths and limitations of this study

- This review was conducted with methodological rigour, including assessment of the risk of bias and the quality of evidence; such information is not available in previous systematic reviews related to the subject.

- This study has explicit eligibility criteria, priority of primary and secondary outcomes, comprehensive and extensive search in the databases, with independent and peer reviews for each study and use of Grading of Recommendations Assessment, Development and Evaluation to assess the quality of the evidence and the strength of recommendation for the outcomes included in the meta-analysis.

- The primary studies included were a limiting factor for the findings of this review due to methodological bias observed in the included randomised controlled trials, as well as the differences observed in the types of cardiovascular diseases, types and dosages of local anaesthetics and vasoconstrictors.

\section{INTRODUCTION}

Cardiovascular diseases (CVD) are one of the causes of most premature deaths worldwide, representing $31 \%$ of all deaths. It is estimated that in 2012 CVD were the main cause of death in the world with approximately 17.5 million deaths. In 2002, three-quarters of CVD deaths occurred in low-income or middle-income countries. CVD comprises essential hypertension, rheumatic heart diseases, ischaemic heart diseases, cerebrovascular diseases, heart inflammatory diseases and so forth. ${ }^{1}$

In the dental office, the presence of patients with complex diseases such as CVD is increasingly common. These patients have access to better treatments and medications, 


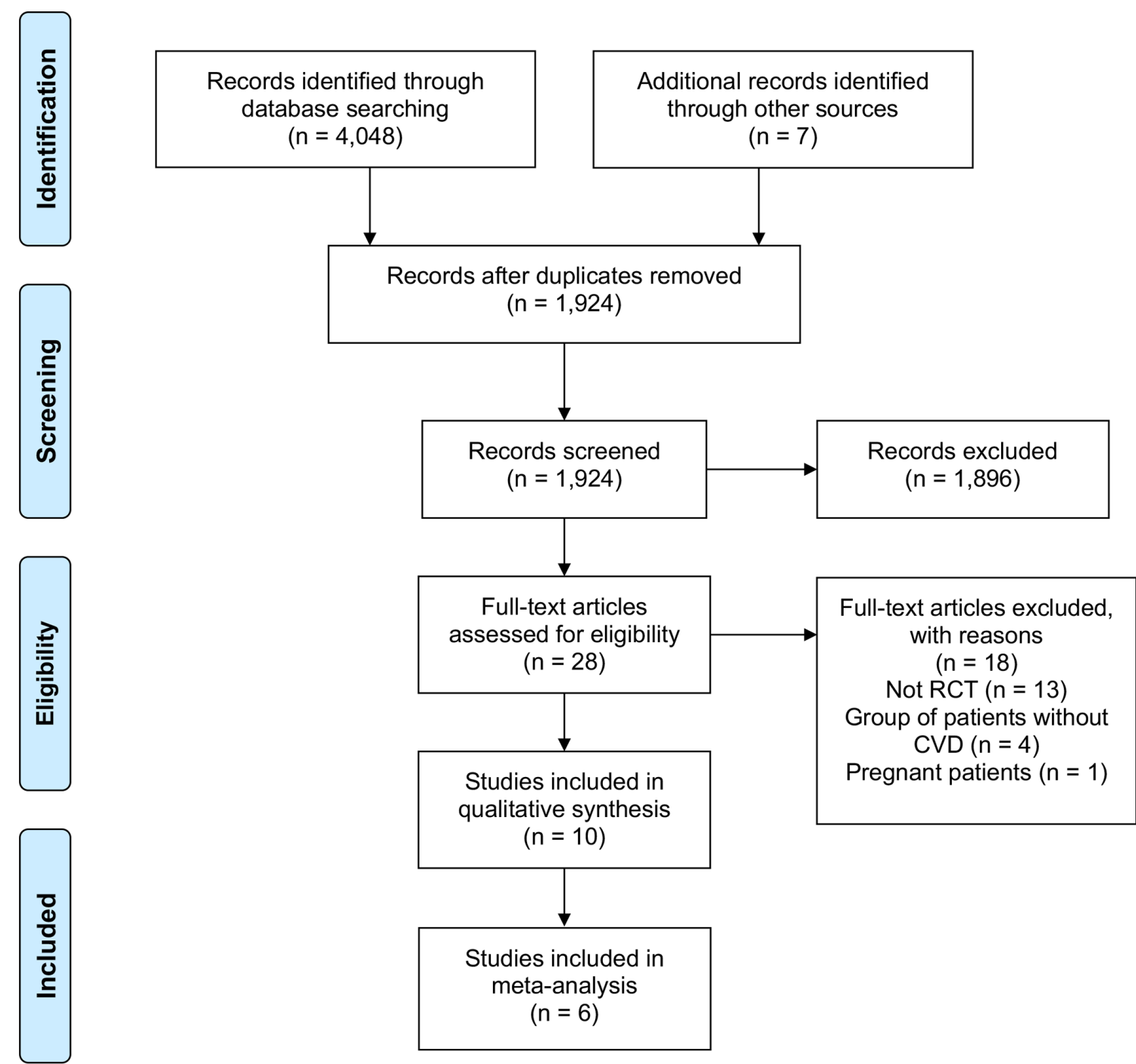

Figure 1 Flow chart for literature search and study selection. CVD, cardiovascular disease; RCT, randomised controlled trial.

which makes it possible to perform treatment in private dental clinics that previously was only executed by specialised hospitals. ${ }^{23}$ However, careful evaluations should be conducted before beginning dental treatment in patients with CVD in order to control stress and mainly to block nerve transmission of pain, thereby minimising transient episodes that may trigger negative cardiovascular outcomes. ${ }^{3}$

The use of local anaesthetics (LAs) and analgesics can control pain, while sedatives control the anxiety during dental procedures. ${ }^{34}$ However, the use of LA has been the baseline of pain control for dental procedures for several decades. ${ }^{56}$

LAs are combined with vasoconstrictors to increase duration of anaesthetic effect, reduce systemic toxicity and optimise soft tissue haemostasis. ${ }^{6}$ However, despite the beneficial properties of vasoconstrictors when combined with LAs, dental professionals are concerned about the adverse effects associated with the vasoconstrictor, mainly with epinephrine, which is the most used vasoconstrictor in dentistry. ${ }^{27}$
These systemic adverse effects are linked to inadequate procedures such as intravascular injection, high-dose injections, drug interactions or instant absorption of the anaesthetic agent when it is injected into an extremely vascular area that could induce adverse cardiovascular effects, especially in patients with CVD. ${ }^{38-10}$

Another factor for adverse effects is the concentration used in LAs. Currently, a greater dilution of the vasoconstrictor is recommended, mostly used at a concentration of 1:100 000 for surgical procedures and, for other procedures, with a dilution of up to $1: 200000 .{ }^{26}$ Nevertheless, for long and/or surgical procedures, LAs without vasoconstrictor do not offer a satisfactory anaesthetic duration, which can cause pain resulting in systemic endogenous release of catecholamines (particularly norepinephrine) and causing negative cardiovascular outcomes. ${ }^{11-13}$

A previous study reported that the stress-induced release of catecholamines could be $>10$ times greater than the basal level. ${ }^{14}$ In stressful situations, such as pain and anxiety, the released endogenous catecholamines may also reach concentrations higher than the low epinephrine 


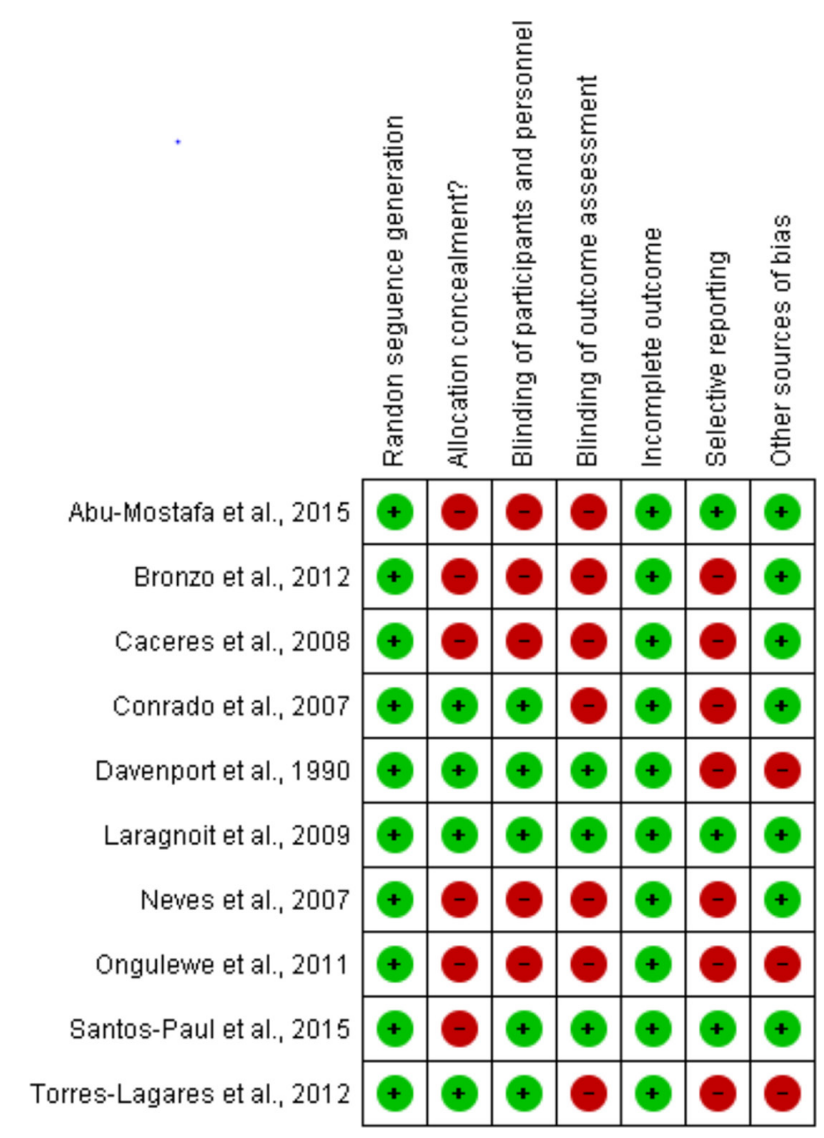

Figure 2 Risk of bias summary: review authors' judgements.

concentrations used in dental LA. ${ }^{14}{ }^{15}$ Thus, the literature recommends using the lowest effective concentration of epinephrine as possible for patients with CVD, both for dermatological and dental procedures. ${ }^{9}{ }^{13} \mathrm{~A}$ few decades ago, the maximum dose of epinephrine in patients with cardiovascular disease was set at up to $200 \mu \mathrm{g} .{ }^{16}$ However, over the years several studies and guidelines on this subject have been published and suggested that $36-54 \mu \mathrm{g}$ of epinephrine appear to be tolerated in most patients with hypertension or other cardiovascular diseases. ${ }^{217}$

Previously two systematic reviews analysed the most frequent complications in patients with CVD after dental local anaesthesia with vasoconstrictor, disclosed in ECG arrhythmias. ${ }^{12}{ }^{13}$ However, both reviews differed from the present study. Bader et al did not describe the inclusion criteria and risk of bias. ${ }^{12}$ In addition, the authors included non-randomised clinical trials and a group of patients without CVD. Godzieba et al also included non-randomised clinical trials and patients without CVD. ${ }^{13}$

LA have a long history of safety and efficacy in dental patients if used in recommended doses and techniques. ${ }^{36}$ However, dental professionals still have doubts about their use in patients with CVD, especially when combined with vasoconstrictor. ${ }^{13}$ Thus, this systematic review evaluated the safety in the use of LA with vasoconstrictor and determined the risk of cardiovascular events in patients with GVD.

\section{METHODS AND ANALYSES}

The systematic review was performed according to the recommendations specified in the Cochrane Handbook for Interventional Reviews and reported according to the Preferred Reporting Items for Systematic Reviews and Meta-Analyses statement. ${ }^{18}$

\section{Protocol and registration}

The protocol of this systematic review was registered on the PROSPERO_International Prospective Register of Systematic Reviews (registration number CRD42016045421).

\section{Eligibility criteria \\ Inclusion criteria \\ Patients}

Adult patients with CVD (essential hypertension, rheumatic heart diseases, ischaemic heart diseases, cerebrovascular diseases, and heart inflammatory diseases). ${ }^{1}$

\section{Interventions}

One arm wherein patients received LA with vasoconstrictors compared with another arm wherein patients received LAs without vasoconstrictors.

\section{Procedures}

Patients who undergo tooth extraction, dental restorations, treatment and periodontal surgery, among others.

\section{Type of study}

Considering that observational studies increase the risk of bias to answer this question, the study design that can generate high quality evidence, according to the evidence hierarchy, would be the randomised controlled trials (RCTs). We include two types of RCT designs. In the first type, patients are randomised to receive either LAs with vasoconstrictors during the first dental procedure or LAs without vasoconstrictors during the second dental procedure or vice versa. In the second type, patients are randomised to receive only one type of LA, with or without vasoconstrictors, during the dental procedure.

\section{Language}

Any language without restriction.

\section{Outcomes measures}

The safety of the use of LAs with vasoconstrictors in patients with CVD was based on the number of reports considering the following primary and secondary outcomes:

\section{Primary outcomes}

- death;

- mortality by a specific cause;

- stroke;

- acute myocardial infarction;

- hospitalisation;

- pain;

- bleeding;

- arrhythmias. 


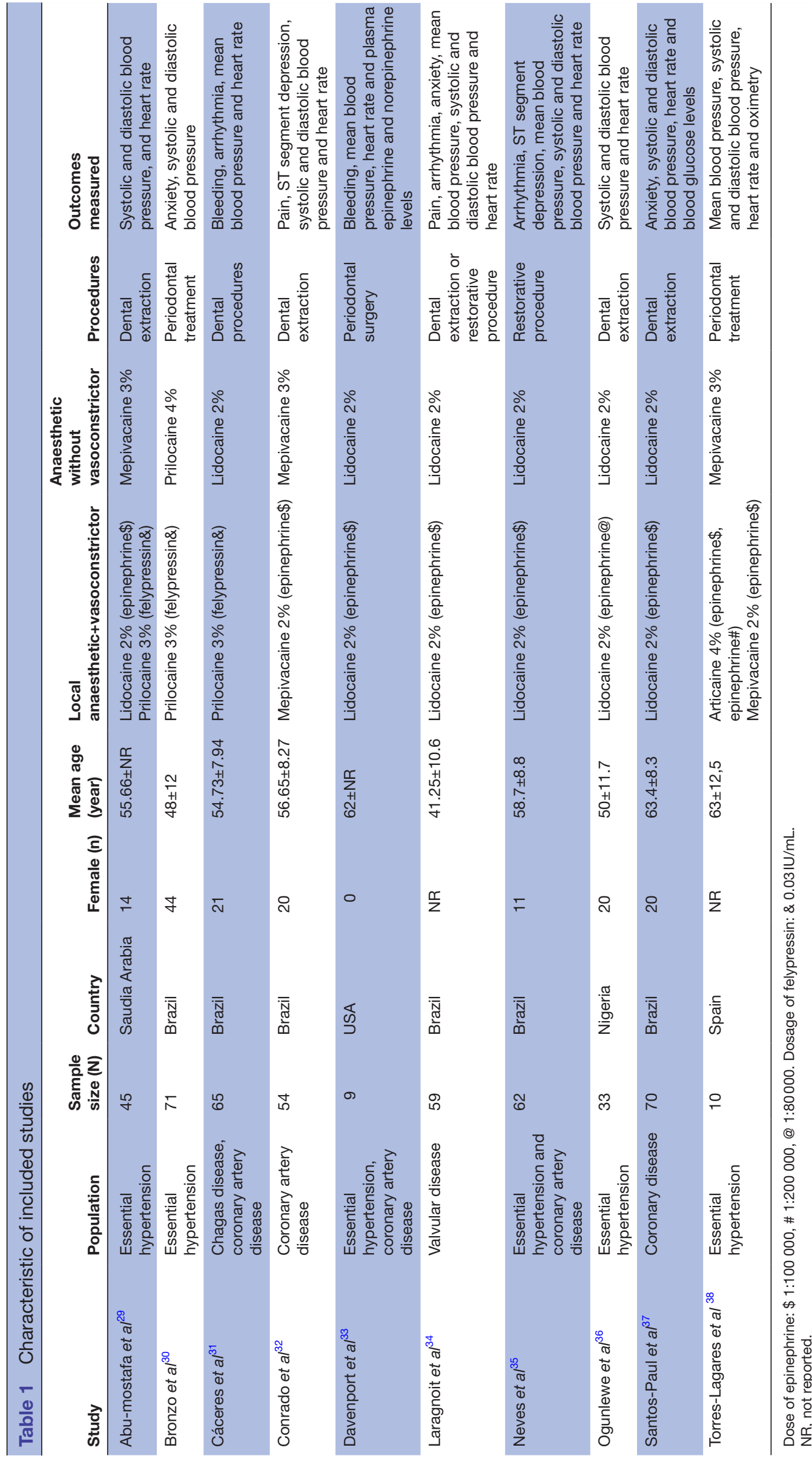


Secondary outcomes

- ST segment depression;

- anxiety;

- adverse effects;

- changes in haemodynamic parameters.

\section{Exclusion criteria}

We exclude studies involving patients with untreated or out-of-control essential hypertension or any type of CAD, who were pregnant or breast feeding, who were allergic to the LAs used in the studies, with out-of-control diabetes mellitus, or who have had recent myocardial infarction, cancer, and malignant hypertension.

\section{Search methods for primary studies \\ Electronic searches}

The following electronic databases were searched: the Cochrane Central Register of Controlled Trials (CENTRAL) part of The Cochrane Library; MEDLINE (Ovid); EMBASE (Ovid); Healthstar (Ovid); CINAHL (Cumulative Index to Nursing and Allied Health Literature) and Web of Science, from their inception to January 2020, without restrictions on the language and date of publication.

\section{Searching other resources}

We performed search in registration of clinical trials: https://clinicaltrials.gov, WHO clinical trials registry, http://www.ensaiosclinicos.gov.br; trials registry and bank of Brazil thesis (CAPES); conference proceedings of the Brazilian Congress of Cardiology, in the Brazilian Congress of Anesthesiology and in the International Congress of Dentistry (CIOSP). Two reviewers analysed the reference list or quotations found in secondary studies to verify and identify possible eligible studies.

\section{Search strategy}

The search strategy was individually conducted by type of dental intervention; type of anaesthetic and type of CVD. We have adapted the search strategy according to each database. The search strategy in MEDLINE (via Ovid) is in online supplemental appendix 1.

\section{Eligibility determination}

Six reviewers (CCG vs CCB vs JOA and RHLM vs NKA vs JCR) working in trio independently evaluated whether summaries are in accordance with eligibility criteria. Discordances were resolved by consensus, and contentious issues were discussed with a third reviewer (LCL).

To exclude duplicate articles, reviewers analysed all eligible articles and identified those with one or more authors in common. In case of duplicate publications, we used the article with more complete data.

\section{Data extraction}

Six reviewers (CCG vs CCB, JOA vs RHLM and NKA vs JCR), working in pairs and independently extracted data and recorded information regarding patients, methods, interventions, outcomes and missing outcome data using standardised and pretested data extraction forms with instructions (figure 1). Before initiating data extraction, we conducted calibration exercises to ensure consistency among the reviewers, both in screening and data extraction. We contacted the study authors as necessary to resolve any uncertainties. Reviewers resolved disagreements by discussion, and one arbitrator (LCL) judged unresolved disagreements.

\section{Risk of bias in individual studies}

Using a modified version of the Cochrane collaboration risk of bias tool, ${ }^{19} 20$ the same pairs of reviewers independently rated the risk of bias for each RCT according to the following criteria: random sequence; allocation concealment; blinding of the patient, healthcare professionals, outcome assessors, data collectors and data analysts; incomplete outcome data; selective outcome reporting; and major baseline imbalance.

Reviewers gave response options of 'definitely yes', 'probably yes', 'probably no' and 'definitely no' for each of the domains, with the options 'definitely yes' and 'probably yes' ultimately being assigned a low risk of bias and 'definitely no' and 'probably no' as having a high risk of bias. ${ }^{21}$ Reviewers resolved disagreements by discussion, and one arbitrator (LCL) judge unresolved disagreements. Risk of bias of RCTs included are in figure 2 and online supplemental appendix 2.

\section{Explaining the heterogeneity of evidence}

Possible explanations for heterogeneity included: (a) age - the older the age, the higher the risk of cardiovascular transient episodes; (b) gender-women outnumber men in deaths due to CVD; (c) vasoconstrictor typevasoconstrictors are linked to receptors $\alpha$ and $\beta$. However, some of these are more often linked to cardiac receptor $\beta$ (except for felypressin, which links to the vasopressin receptor v1, present in the smooth muscles of blood vessel walls, raise cardiac frequency and thus, higher risks of transient episodes are expected) ${ }^{22}$; (d) vasoconstrictor concentration-which may vary from a 1:2500 to a 1:200 000 greater risk is expected with higher vasoconstrictor concentration; (e) dental procedure duration-the longer the duration to perform the procedure (surgical or periodontal procedures take longer than restorative procedures), the higher the concentration of anaesthetic agent necessary, and the stronger the toxicity to the cardiovascular system, thereby increasing the risk of transient episodes in long-duration procedures; (f) dental procedure type-usually surgical procedures (periodontal, extraction and implantation) trigger great stress in the patient, thus increasing the risk of transient episodes. For the all outcomes, subgroup analyses were not possible due to the low number of studies included.

We ranked heterogeneity associated with pooled effect estimates with the use of the $\chi^{2}$ test and the $\mathrm{I}^{2}$ statistic. ${ }^{23}$ The following heterogeneities were considered: $0 \%-25 \%$ (low heterogeneity), $50 \%$ (moderate heterogeneity) and $75 \%$ (high heterogeneity). ${ }^{20}$ 


\section{Data synthesis}

Analyses were conducted for each vasoconstrictor and for each outcome of interest. Confidence in the findings was determined by estimates for each body of evidence. The studies which reported continuous outcomes presented the date in standard mean difference (SMD) and 95\% CI and dichotomous outcomes were reported as risk ratio (RR) combined with the $95 \%$ CI.

Other details about the methods adopted for the synthesis of the data can be found in the publication of the protocol of this review. ${ }^{24}$ The random effect in metaanalysis was performed using the Review Manager 5 Software (V.5.3).

\section{Summarising evidence}

The quality of evidence was independently evaluated (confidence in effect estimates) for each outcome reported using Grading of Recommendations Assessment, Development and Evaluation (GRADE). ${ }^{25}$ Results are presented in evidence profiles, as recommended by the GRADE Working Group. ${ }^{26} 27$

In this approach, randomised trials begin with evidence of high quality may have their qualities diminished according to the judgement of one or more of the five categories of limitations presented below: risk of bias (assessed for each study as described previously), inconsistency, indirect evidence, imprecision and publication bias. $^{25}$ We used GRADE methodology to rate confidence in estimates of effect for each outcome as high, moderate, low or very low. Evidence profiles are provided brief presentations of evidence quality and effect magnitude, with the help of the software program GRADEpro (http://ims.cochrane.org/gradepro).

\section{Patient and public involvement}

No patient was involved in this study.

\section{RESULTS}

\section{Literature search results}

From 4048 publications retrieved from the databases, 1924 articles remained for the titles and abstracts selection after removing duplicates. From the 28 preselected papers, 18 were excluded (online supplemental appendix 3) and 10 met eligibility criteria. ${ }^{29-38}$ Six studies 293132343538 were included in the meta-analysis (figure 1).

\section{Description of the studies Methods}

Ten RCTs were included, encompassing a total of 478 patients with CVD, from which 226 patients had coronary artery disease, 226 patients had essential hypertension, 59 patients had valvular diseases and 33 patients had Chagas disease. Table 1 describes the characteristics of the studies in which it was observed that the majority of the studies used lidocaine as LA and epinephrine as a vasoconstrictor. The studies were mainly published in Brazil between 2007 and 2014. The different reasons for exclusion of articles are found in online supplemental appendix 3.

Intervention

Eight studies ${ }^{3032-38}$ used the same LA both in the control and intervention groups; two studies ${ }^{29} 38$ included more than one group in the intervention group; five studies ${ }^{33-37}$ used lidocaine both in the intervention and control groups; one study ${ }^{30}$ used prilocaine both in the intervention and control groups; two studies ${ }^{32} 38$ used mepivacaine both in the intervention and control groups and three studies ${ }^{29} 3138$ used different LA solutions between the intervention and control groups.

Eight studies ${ }^{29}$ 32-38 used the vasoconstrictor epinephrine; followed by felypressin, which was present in three studies $^{29-31}$ and only one study ${ }^{29}$ used both epinephrine and felypressin (table 1).

\section{Participants}

Five studies 2930333638 included patients with essential hypertension. Two studies ${ }^{32} 37$ included patients with coronary artery disease. Two studies ${ }^{33}$ included patients with essential hypertension and coronary artery disease. One study ${ }^{34}$ included patients with valvular diseases, and one study ${ }^{31}$ included patients with Chagas disease and coronary artery disease.

\section{Risk of bias in the included studies}

Randomisation and allocation

From the 10 RCTs included, 3 studies $^{30} 33$ used the crossover design, what reduces the quality of the evidence and performed washout periods between $10 \mathrm{~min}$ and 3 weeks. Randomisation by computer was performed by only one study. ${ }^{38}$ Two studies ${ }^{33} 34$ used the random number table. Two studies ${ }^{29} 32$ did a draw of the ID cards. Five studies ${ }^{30} 31$ 35-37 did not mention the randomisation method (figure 2 and online supplemental appendix 2).

The allocation concealment method was considered of low risk of bias in one study, ${ }^{38}$ when randomisation was performed by computer.

\section{Blinding}

Two studies ${ }^{34} 37$ reported performing double-blinding, but only one study ${ }^{34}$ partially described. One study ${ }^{37}$ only mentioned that the blinding was performed, without an explanation of the method. Five studies ${ }^{29-313536}$ were not conducted blinded.

Only two studies ${ }^{32} 34$ did not mention the blinding but used allocation concealment delivered in sealed envelopes, and the cartridges were covered with a white strip.

\section{Loss to follow-up}

The studies reported no loss to follow-up.

Selective reporting of outcomes

Three studies ${ }^{29} 3437$ had the registry of clinical trial reporting prespecified outcomes. Two studies ${ }^{34}{ }^{37}$ made the registry at ClinicalTrials.gov and one study ${ }^{29}$ at the Institute Research Center. 


\section{Other potential source of bias}

Four studies ${ }^{29-3134}$ mentioned that there was no external funding. One study ${ }^{37}$ received Brazilian funding through the São Paulo State Research Support Foundation (FAPESP), which is non-profit.

Six studies ${ }^{29-32} 3435$ declared no potential conflicts of interest. One study ${ }^{34}$ mentioned both no external funding sources and no potential conflict of interest only in the registry of clinical trials

\section{Reported primary outcomes}

None of the studies reported death, mortality by specific cause, stroke, acute myocardial infarction or hospitalisation. The only primary outcomes reported by the authors included in this review were pain, bleeding and arrhythmias (table 1). Due to the small number of studies and the lack of numerical data, it was not possible to perform the data meta-analysis of pain and bleeding. The reports of these outcomes were descriptive and qualitative.

\section{Pain}

Two studies ${ }^{32} 34$ evaluated the pain outcome. Conrado et $a l$ assessed the pain outcome at the extraction site in 54 patients with coronary disease and observed pain report in only one patient from the intervention group (mepivacaine $2 \%$ with epinephrine 1:100 000), and in 9 patients from the control group (mepivacaine $3 \%$ without vasoconstrictor). The authors did not describe how they have assessed pain and explained that the only one case of pain in the intervention group was caused by a tooth that was ankylosed. $^{32}$

Laragnoit et al examined 59 participants with several valvular diseases and described the results only in a qualitative way. It was observed that there were more complaints of pain in the control group (lidocaine 2\% without vasoconstrictor) compared with the intervention group (lidocaine $2 \%$ with epinephrine $1: 100000$ ). ${ }^{34}$ The authors did not describe how they assessed pain.

\section{Bleeding}

Two studies ${ }^{3133}$ evaluated the bleeding outcome. Cáceres $e t$ al did not report bleeding during the procedures. In both groups, authors did not describe how they assessed this outcome. ${ }^{31}$ Davenport et al examined nine participants in the control and intervention groups and observed that all participants in the intervention group (lidocaine $2 \%$ with epinephrine 1:100 000) obtained adequate haemostasis versus seven participants with inadequate haemostasis in the control group (lidocaine $2 \%$ without vasoconstrictor). The authors did not describe how they assessed bleeding. ${ }^{33}$

\section{Arrhythmia}

Three studies ${ }^{31} 3435$ assessed this outcome. Cáceres et al analysed the presence of ventricular extrasystoles that remained stable in different measured moments, with a similar behaviour in both groups. ${ }^{31}$

Laragnoit et al reported eight patients with arrhythmia, being five patients from the intervention group (lidocaine $2 \%$ with epinephrine $1: 100000$ ) and three patients in the control group (lidocaine $2 \%$ ), with no observed statistical difference between both groups. ${ }^{34}$

Neves et al reported seven patients with arrhythmia, being three patients $(11.1 \%)$ from the intervention group (lidocaine 2\% with epinephrine 1:100 000) and four patients $(13.8 \%)$ from the control group (lidocaine $2 \%$ without vasoconstrictor), with no observed significant statistical difference between the two groups. ${ }^{35}$

The meta-analysis demonstrated no difference in the arrhythmias between the groups (RR $1.24,95 \%$ CI 0.47 to 3.28 low quality evidence) (figure 3 , table 2 ).

\section{Reported secondary outcomes}

Adverse effects were not reported in the studies.

\section{ST segment depression}

Two studies ${ }^{32} 35$ evaluated the presence of ischaemic episodes (measured as ST segment depression).

Conrado et al observed the occurrence of the ST segment depression $>1 \mathrm{~mm}$ in three patients in the intervention group (mepivacaine 2\% with epinephrine 1:100 $000)$ during anaesthetic injection. No event was observed in the control group (mepivacaine 3\% without vasoconstrictor) and no statistical difference was observed between the groups. ${ }^{32}$

Neves et al observed ST segment depression $>1 \mathrm{~mm}$ in four patients $(14.8 \%)$ in the intervention group (lidocaine $2 \%$ with epinephrine $1: 100000)$ and in six patients $(20.7 \%)$ in the control group (lidocaine 2\% without vasoconstrictor), with no significant statistical difference between the groups. ${ }^{35}$

The meta-analysis demonstrated no difference in the ST segment depression between the groups (RR 1.53, 95\% CI 0.17 to 13.72 low quality evidence) (figure 4 , table 2 ).

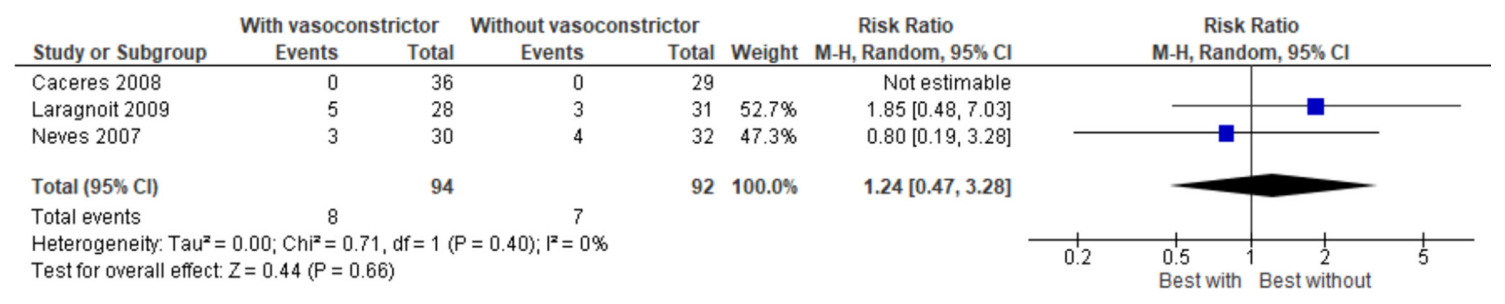

Figure 3 Presence of arrhythmia associated with the use of anaesthetic with vasoconstrictor versus with the use of anaesthetic without vasoconstrictor. 


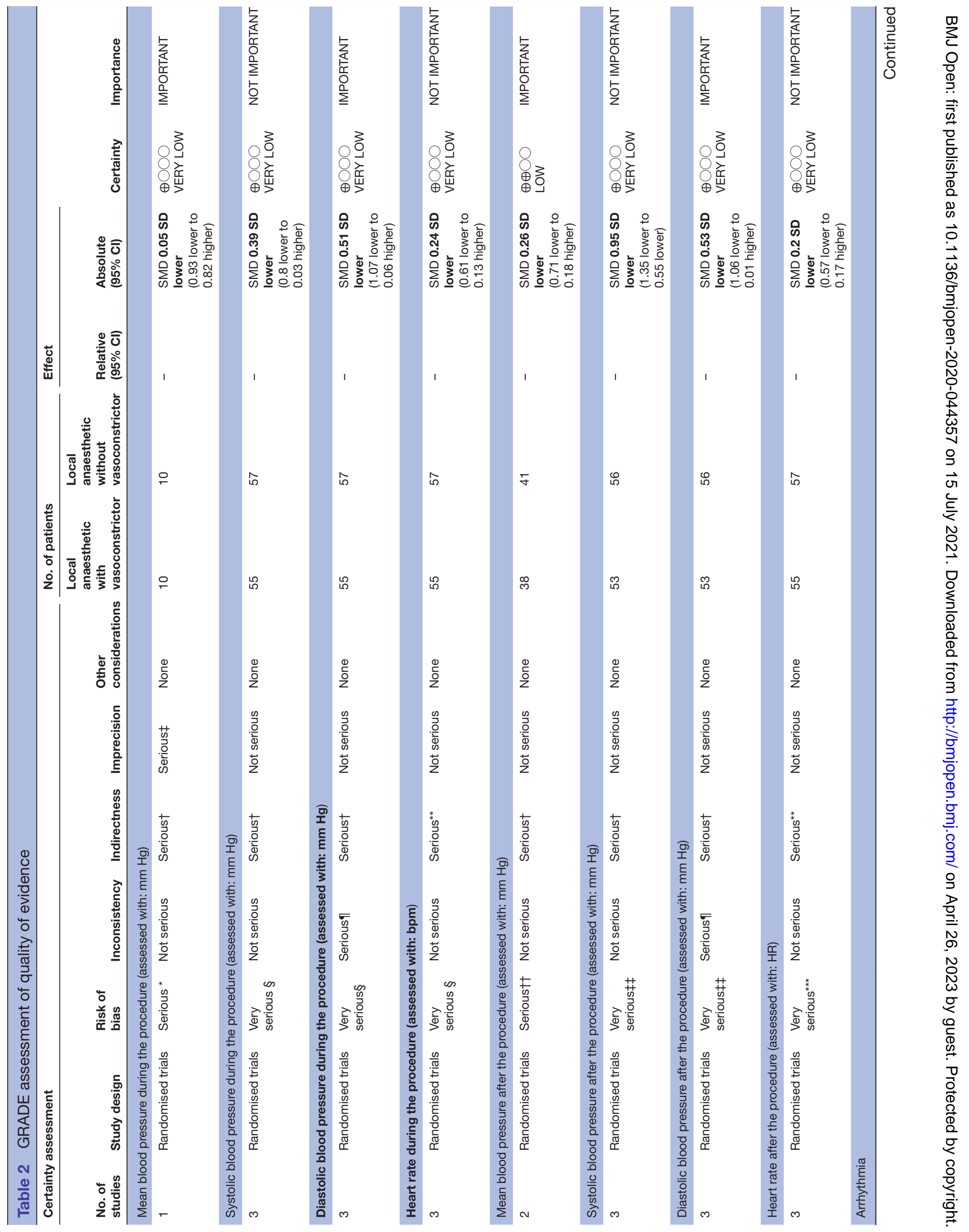




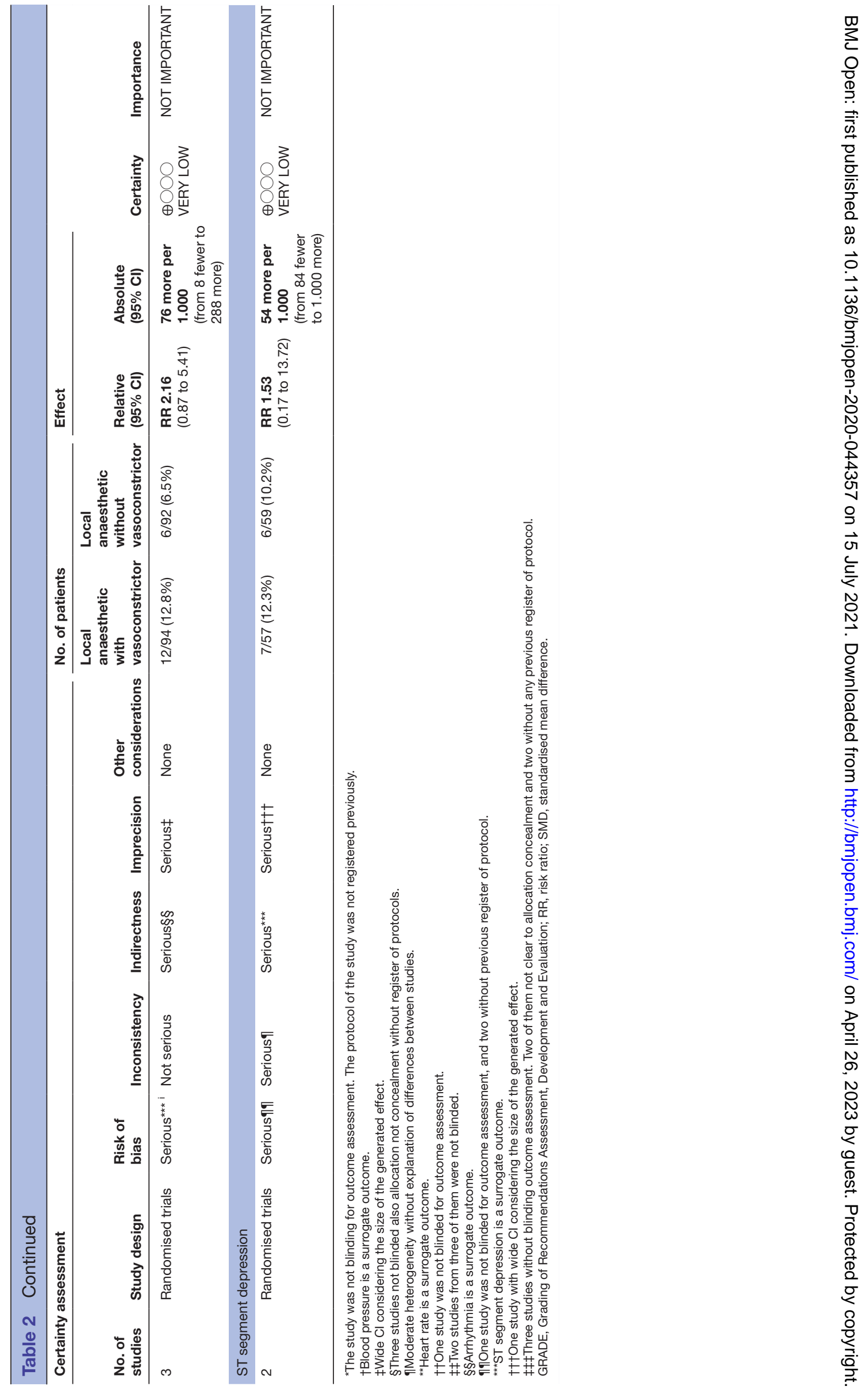




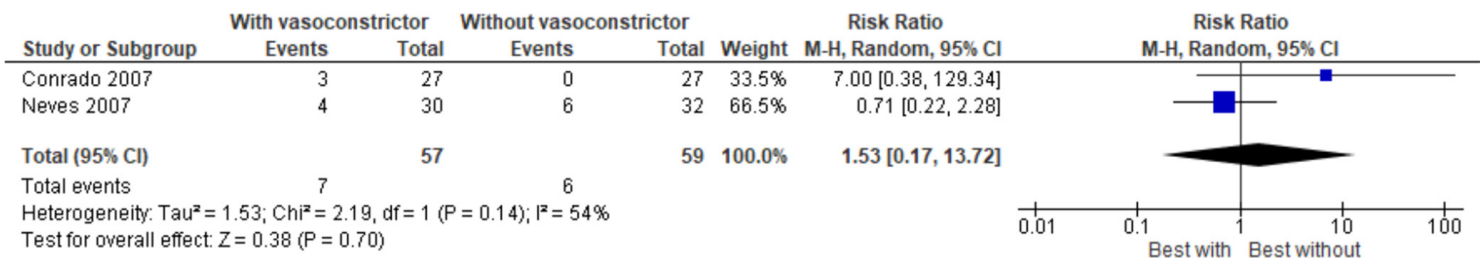

Figure 4 Presence of ST segment depression associated with the use of anaesthetic with vasoconstrictor versus with the use of anaesthetic without vasoconstrictor.

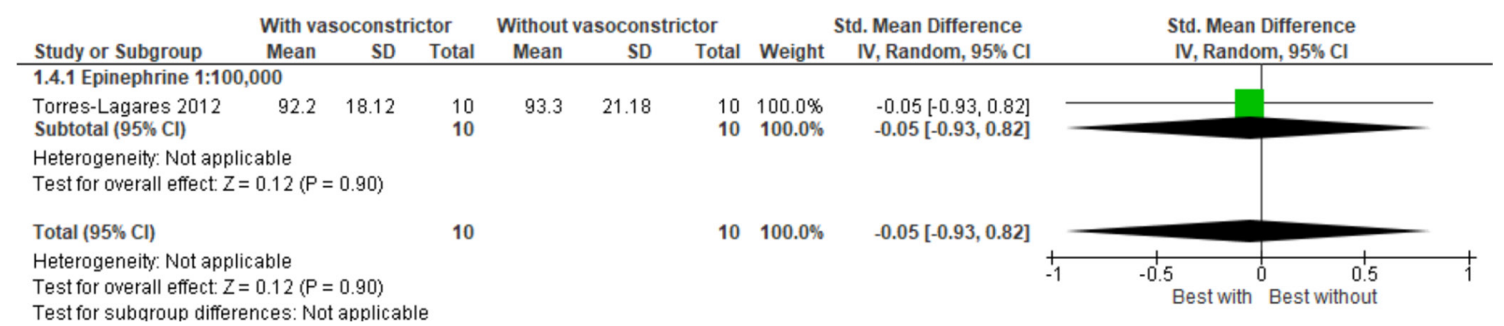

Figure 5 Mean blood pressure values associated with the use of anaesthetic with vasoconstrictor versus with the use of anaesthetic without vasoconstrictor, during the procedure period.

\section{Anxiety}

Two studies ${ }^{34} 37$ evaluated the anxiety outcome. Laragnoit et al assessed the anxiety of patients using the Spielberger State-Trait Anxiety Inventory scale before the procedure and reported no difference in the mean values of anxiety levels between the intervention and control groups. ${ }^{34}$

Santos-Paul et al assessed the anxiety of patients using Buchanan and Niven facial scale in different periods ( 1 hour before the procedure, $5 \mathrm{~min}$ after the procedure and 1 hour after the procedure). They reported no significant difference between the control and intervention groups at any of the evaluated time periods. ${ }^{37}$

\section{Mean blood pressure}

Five studies ${ }^{31}{ }^{33-35} 38$ evaluated the mean blood pressure values. In four studies, ${ }^{31}{ }^{33-35}$ there were no significant statistical difference between the assessed groups. Torres-Lagares et al reported increase in the average of mean blood pressure in the intervention group (mepivacaine $2 \%$ with epinephrine $1: 100000$ ) in comparison to the other three intervention groups (articaine $4 \%$ with epinephrine 1:200 000, articaine 4\% with epinephrine 1:100 000, mepivacaine $3 \%$ without vasoconstrictor). ${ }^{38}$ Three studies ${ }^{31} 3335$ mention their results only in graphs and it was not possible to perform meta-analysis.
Meta-analysis was conducted with the studies by Laragnoit $e t$ al and Torres-Lagares $e t a l .{ }^{34} 38$ No difference was observed in the mean blood pressure between the groups during the procedure period (SMD $-0.05,95 \%$ CI -0.93 to 0.82 , very low quality evidence), and after the procedure period (SMD $-0.26,95 \%$ CI -0.71 to 0.18 , low quality evidence). Time periods have been adapted to carry out the meta-analysis (figures 5 and 6 , table 2 ).

\section{Systolic blood pressure}

Eight studies ${ }^{29} 3032$ 34-38 evaluated this outcome. In seven studies $^{30} 32$ 34-38 there were no significant statistical difference between the assessed groups.

Abu-Mostafa et al observed a significant increase in the systolic blood pressure after dental extraction in the control group (mepivacaine $3 \%$ without vasoconstrictor) compared with the intervention group (lidocaine 2\% with epinephrine 1:80 000) after the procedure. ${ }^{29}$

Four studies ${ }^{30} 323637$ could not be included in the metaanalysis because their data were presented in graphs. Even after several attempts to contact the authors, they did not respond. Additionally, unsuccessful attempts were made to extract data using the Digitizelt software.

Meta-analysis showed no difference in systolic blood pressure while using LA with vasoconstrictor compared

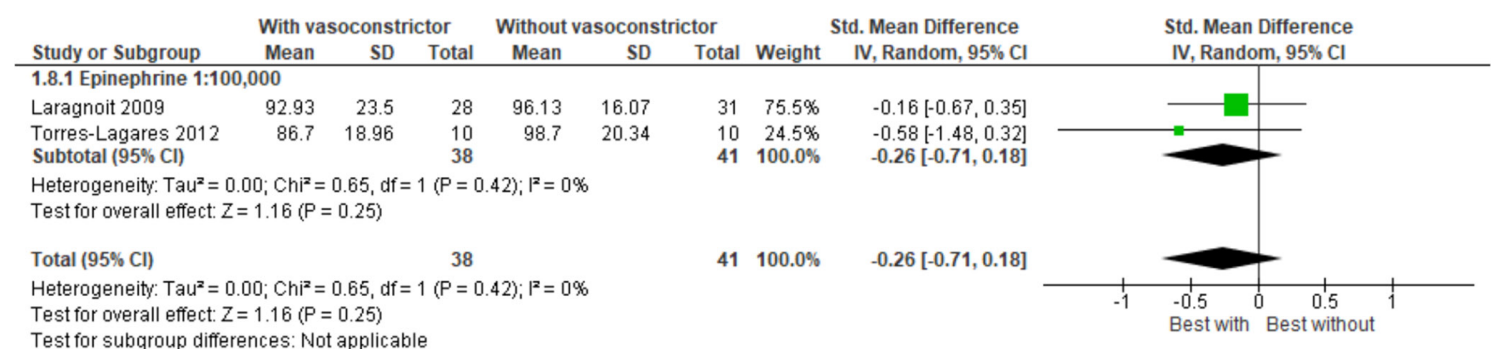

Figure 6 Mean blood pressure values associated with the use of anaesthetic with vasoconstrictor versus with the use of anaesthetic without vasoconstrictor, after the procedure period. 


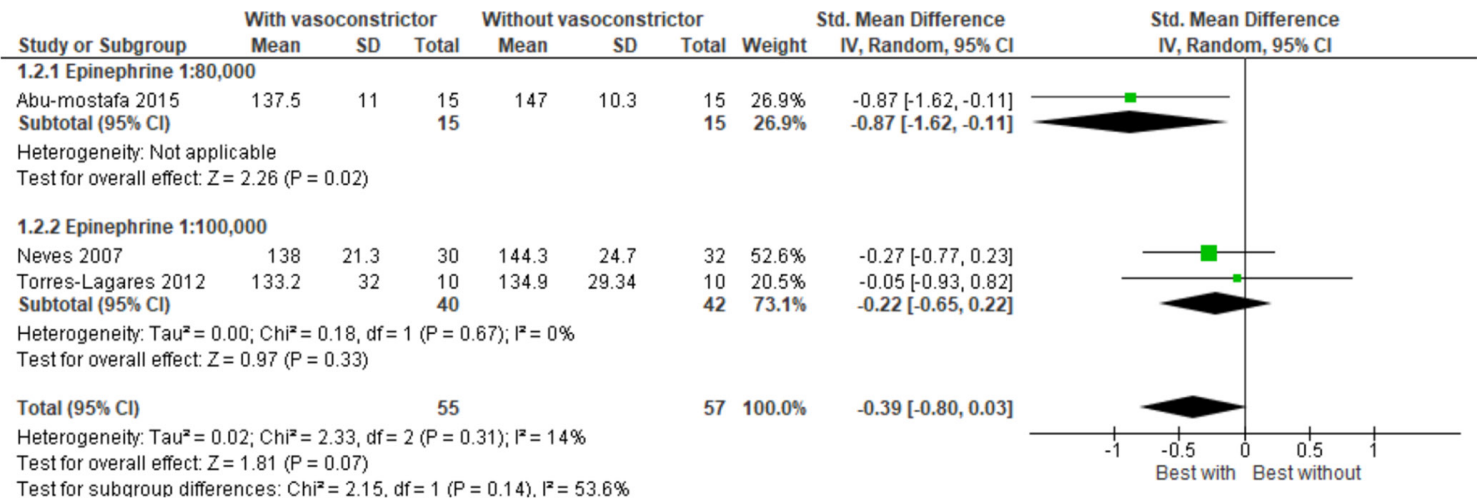

with using only LA without vasoconstrictor during the procedure period (SMD $-0.39,95 \%$ CI -0.80 to 0.03 , very low quality evidence) (figure 7, table 2). After the procedure period, meta-analysis demonstrated a decrease in the systolic blood pressure with the use of LA with vasoconstrictor (SMD $-0.95,95 \% \mathrm{CI}-1.35$ to -0.55 ) (figure 8 , table 2).

\section{Diastolic blood pressure}

Eight studies ${ }^{29} 3032$ 34-38 evaluated the average diastolic blood pressure. In six studies, ${ }^{29} 3234-37$ there was no significant statistical difference between the assessed groups.

In the study by Bronzo et al, there was an increase in diastolic blood pressure during the dental procedures in both groups. However, in the intervention group (prilocaine $2 \%$ with felypressin $0.03 \mathrm{IU}$ ) diastolic blood pressure was greater than in the control group (prilocaine $4 \%$ without vasoconstrictor). ${ }^{30}$ Torres-Lagares et al reported diastolic blood pressure values significantly higher in the intervention group (mepivacaine $2 \%$ with epinephrine $1: 100000)$ in comparison to the other two intervention groups (articaine 4\% with epinephrine 1:200 000; articaine $4 \%$ with epinephrine 1:100 000) and control group (mepivacaine $3 \%$ without vasoconstrictor). ${ }^{38}$

Four studies ${ }^{30} 323637$ could not be included in the metaanalysis because their data were presented in graphs. Even after several attempts to contact the authors, they did not respond. Additionally, unsuccessful attempts were made to extract data using the Digitizelt software.

Meta-analysis showed no statistical difference between the diastolic blood pressure during the procedure (SMD $-0.51,95 \%$ CI -1.07 to 0.06 ) and after the procedure periods (SMD $-0.53,95 \%$ CI -1.06 to 0.01 ). However, it was noted that there was a tendency, with no statistical significance, in favour of the use of LA with vasoconstrictor (figures 9 and 10). The quality of evidence was considered very low for both during and after the procedure periods (table 2).

\section{Heart rate}

Nine studies ${ }^{29}{ }^{31-38}$ assessed this outcome and in any of them significant difference between the groups was found. Six studies ${ }^{31-34} 3637$ could not be included in the meta-analysis because their data were presented in graphs. Even after several attempts to contact the authors, they did not respond. Additionally, unsuccessful attempts were made to extract data using the Digitizelt software.

Only three studies ${ }^{29} 3538$ could be included in metaanalysis from which numerical data were available. Metaanalysis showed no statistical difference for the periods during (SMD $-0.24,95 \% \mathrm{CI}-0.61$ to 0.13 ) and after the procedure (SMD $-0.20,95 \%$ CI -0.57 to 0.17 ) for heart rate between the groups (figures 11 and 12), being the evidence considered of very low quality (table 2 ).

\begin{tabular}{|c|c|c|c|c|c|c|c|c|c|}
\hline \multirow[b]{2}{*}{ Study or Subgroup } & \multicolumn{3}{|c|}{ With vasoconstrictor } & \multicolumn{3}{|c|}{ Without vasoconstrictor } & \multicolumn{2}{|r|}{ Std. Mean Difference } & \multirow{2}{*}{$\begin{array}{l}\text { Std. Mean Difference } \\
\text { IV, Random, } 95 \% \mathrm{Cl}\end{array}$} \\
\hline & Mean & SD & Total & Mean & SD & Total & Weight & IV, Random, $95 \%$ Cl & \\
\hline \multicolumn{9}{|c|}{ 1.6.1 Epinephrine 1:80,000 } & \\
\hline $\begin{array}{l}\text { Abu-mostafa } 2015 \\
\text { Subtotal }(95 \% \mathrm{Cl})\end{array}$ & 133.5 & 10 & $\begin{array}{l}15 \\
15\end{array}$ & 145.8 & 10.5 & $\begin{array}{l}15 \\
15\end{array}$ & $\begin{array}{l}26.2 \% \\
26.2 \%\end{array}$ & $\begin{array}{l}-1.17[-1.95,-0.38] \\
-1.17[-1.95,-0.38]\end{array}$ & \\
\hline \multicolumn{10}{|c|}{ Heterogeneity: Not applicable } \\
\hline \multicolumn{10}{|c|}{ 1.6.2 Epinephrine 1:100,000 } \\
\hline Laragnoit 2009 & 122.36 & 4.98 & 28 & 127.16 & 4 & 31 & $53.5 \%$ & $-1.05[-1.60,-0.51]$ & \\
\hline $\begin{array}{l}\text { Torres-Lagares } 2012 \\
\text { Subtotal }(95 \% \text { Cl) }\end{array}$ & 127.4 & 31.46 & $\begin{array}{l}10 \\
38\end{array}$ & 140.3 & 29.14 & $\begin{array}{l}10 \\
41\end{array}$ & $\begin{array}{l}20.3 \% \\
73.8 \%\end{array}$ & $\begin{array}{r}-0.41[-1.30,0.48] \\
-0.83[-1.43,-0.22]\end{array}$ & \\
\hline \multicolumn{10}{|c|}{$\begin{array}{l}\text { Heterogeneity: Tau }{ }^{2}=0.07 ; C_{i} i^{2}=1.48, d f=1(P=0.22) ; I^{2}=32 \% \\
\text { Test for overall effect: } Z=2.69(P=0.007)\end{array}$} \\
\hline Total $(95 \% \mathrm{Cl})$ & & & 53 & & & 56 & $100.0 \%$ & $-0.95[-1.35,-0.55]$ & \\
\hline \multicolumn{9}{|c|}{$\begin{array}{l}\text { Heterogeneity: } \mathrm{Tau}^{2}=0.00 ; \mathrm{Chi}^{2}=1.87, \mathrm{df}=2(\mathrm{P}=0.39) ; \mathrm{I}^{2}=0 \% \\
\text { Test for overall effect: } Z=4.66(P<0.00001) \\
\text { Test for subaroun differences } \mathrm{Ch}^{2}=0.45 \mathrm{df}=1(\mathrm{P}=0.50)^{2}=0\end{array}$} & 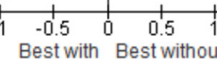 \\
\hline
\end{tabular}

Figure 8 Systolic blood pressure values associated with the use of anaesthetic with vasoconstrictor versus with the use of anaesthetic without vasoconstrictor, after procedure period. 


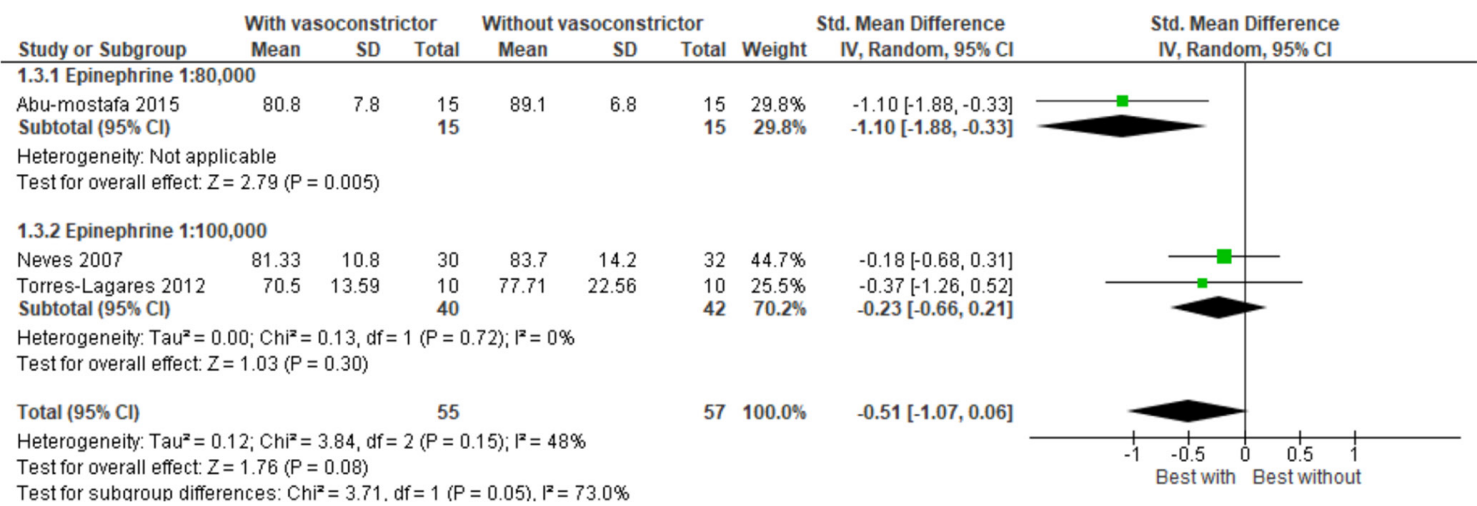

Figure 9 Diastolic blood pressure values associated with the use of anaesthetic with vasoconstrictor versus with the use of anaesthetic without vasoconstrictor, during the procedure period.

\section{DISCUSSION}

\section{Discussion of main findings with the literature}

The use of LA with vasoconstrictor decreased pain and bleeding, but neither outcome could be included in the statistical analysis due to the lack of data. The findings of meta-analysis showed decreasing on the systolic blood pressure with the use of LA with vasoconstrictor compared with control group after the procedure. No significant difference was observed comparing LA with and without the use of vasoconstrictor for the outcomes anxiety, arrhythmia, ST segment depression, mean blood pressure, diastolic blood pressure and rate heart during and after the dental procedure.

In general, the quality of the evidence was considered low for the outcomes evaluated mainly due to the risk of bias, such as lack of blinding, concealment of the allocation not clearly described and problems due to the high heterogeneity between clinical trials and the inaccuracy of the findings.

Considering previous systematic reviews found in literature related to this subject, ${ }^{12}{ }^{13}$ methodological differences and in the proposed objectives, as well as the absence of meta-analysis did not allow the direct comparison of their results with the present study.

Bader et al evaluated the cardiovascular adverse effects risk on the use of LA with epinephrine and the use of epinephrine-impregnated retraction cord. The authors included healthy patients and patients with CVD using LA with or without vasoconstrictor, and they also included nonrandomised clinical trials, different from the objectives and methods of our review. The authors reported that the adverse effects in patients with essential hypertension are uncommon and that there is a small risk for haemodynamic changes, such as blood pressure and heart rate.

Another systematic review ${ }^{13}$ evaluated the use of LA with vasoconstrictor in patients with CVD. However, studies with healthy patients and non-randomised studies were included and outcomes were not prioritised. The review verified 87 complications that occurred after the administration of the LA. Although cardiac arrhythmia was the most frequent outcome, it was not clinically relevant. The authors concluded that use with the maximum limit of four dental cartridges of lidocaine with epinephrine 1:100000 appears to be relatively safe in patients with CVD.

\section{Strengths and limitations of this study}

This study was conducted with methodological rigour, including risk assessment of bias and of quality of evidence; such information is not available in reviews related to the subject. ${ }^{12}{ }^{13}$ Furthermore, the study has explicit eligibility criteria, priority of outcomes (primary and secondary), comprehensive and extensive search in the databases, with independent and peer reviews for each study and use of GRADE to assess the quality of the evidence and the

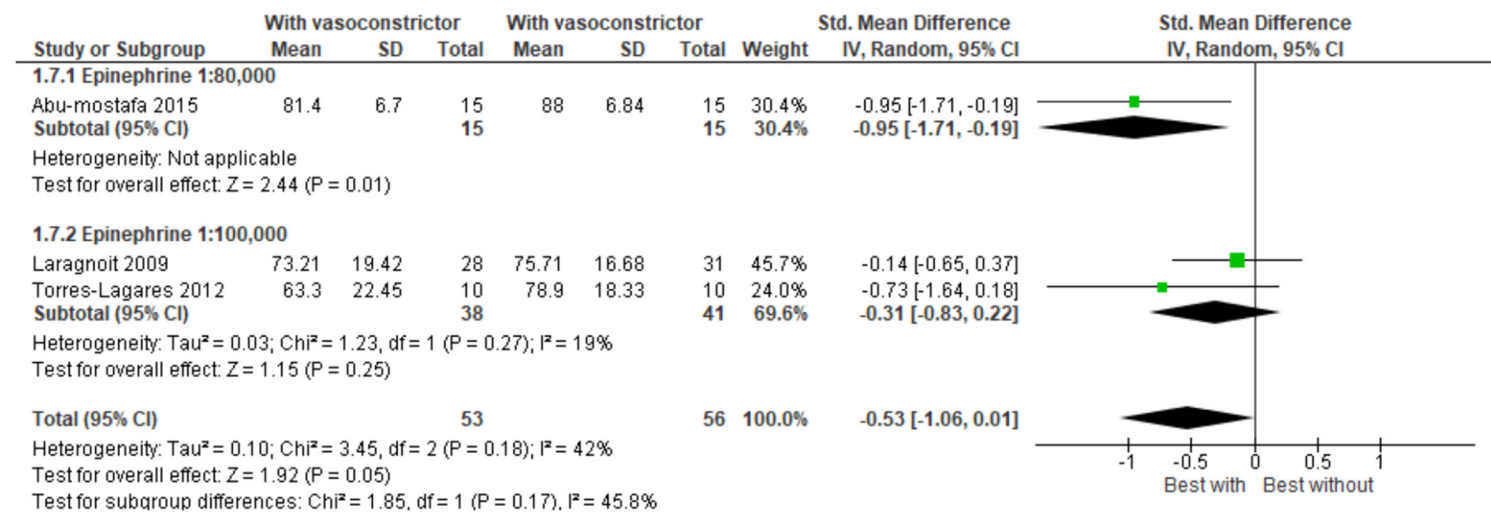

Figure 10 Diastolic blood pressure values associated with the use of anaesthetic with vasoconstrictor versus with the use of anaesthetic without vasoconstrictor, after the procedure period. 


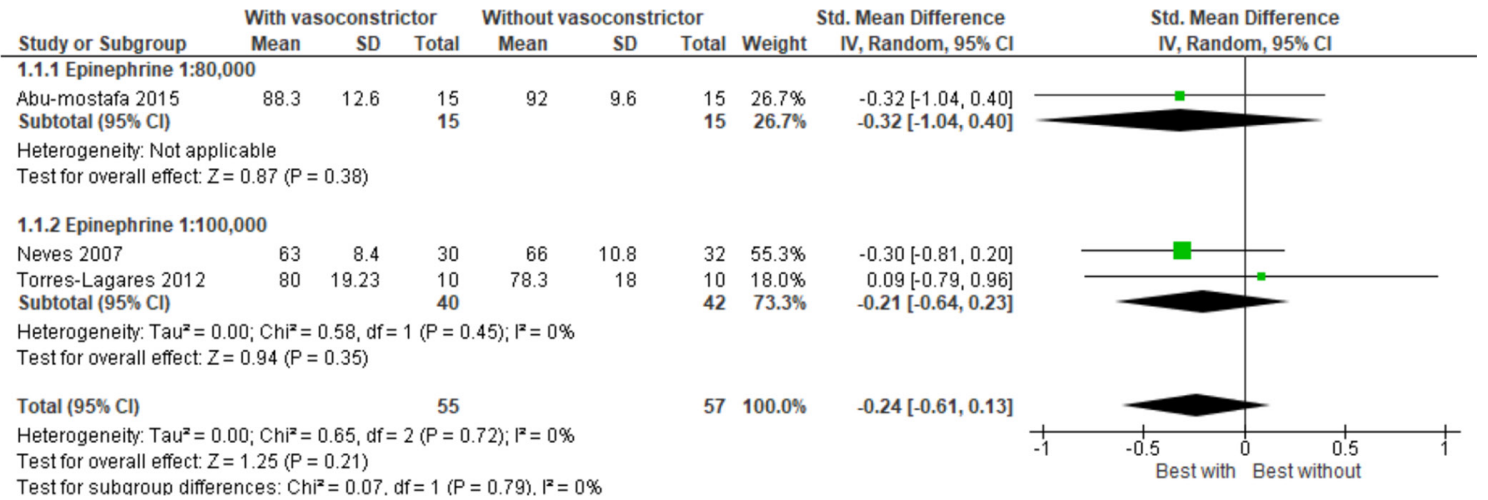

strength of recommendation for the outcomes included in the meta-analysis.

Although the search strategy was carried out in different databases (Cochrane Central Register of Controlled Trials, MEDLINE, EMBASE, Healthstar, CINAHL, Web of Science and ClinicalTrials.gov), coincidentally the included studies were mainly published in Brazil between 2007 and 2014. CVD (mainly stroke and coronary heart disease) has been Brazil's leading cause of death for half a century. ${ }^{39}$ However, CVDs have several aetiological factors related to the population profile (ethnicity, genetic factors, habits, among others). Considering these factors, and that most of the studies included are from Brazil, the present study also indicates the need for further studies related to the topic of this systematic review with different patient profiles.

Considering the possible outcomes, conducting clinical studies with CVD patients is highly complex. In addition, the difficulty of including patients with specific systemic profiles may explain the limited number of types of CVD included in this study. The primary studies included were a limiting factor for the findings of this review due to methodological bias observed in the included RCTs, as well as the differences observed in the types of CVDs, types and dosages of LA and vasoconstrictors. Thus, it was noted a need for more primary studies about the subject, with better methodological accuracy and prioritisation of outcomes in order to increase confidence in findings.

\section{Implications for clinical practice and research}

The LA associated with vasoconstrictor is essential in dental treatment because vasoconstrictor agents counteract the vasodilating action of LA, increasing anaesthetic time and reducing bleeding. ${ }^{6}{ }^{8}$ The findings of this systematic review are limited to some types of CVD and the use of epinephrine and felypressin as vasoconstrictors. Additionally, the low quality of evidence demonstrates that literature needs further studies in order to confirm these results.

Thus, new RCTs with higher methodological rigour are needed to obtain more reliable results, in order to verify the safety of LAs with vasoconstrictor in patients with CVDs. It is also suggested that the professionals use the recommended doses as well as perform the procedure respecting the anaesthetic techniques. ${ }^{269}$ Moreover, communication with the patient's cardiologist can help clarify the patient's clinical condition, to evaluate the care and limitations of the safest dental treatment for each patient. ${ }^{39}$

\section{CONCLUSION}

None of the included studies in this review reported death, mortality by specific cause, stroke or acute myocardial infarction. The results suggest that the use of LA with epinephrine in low doses in adult patients with CVD reduced systolic

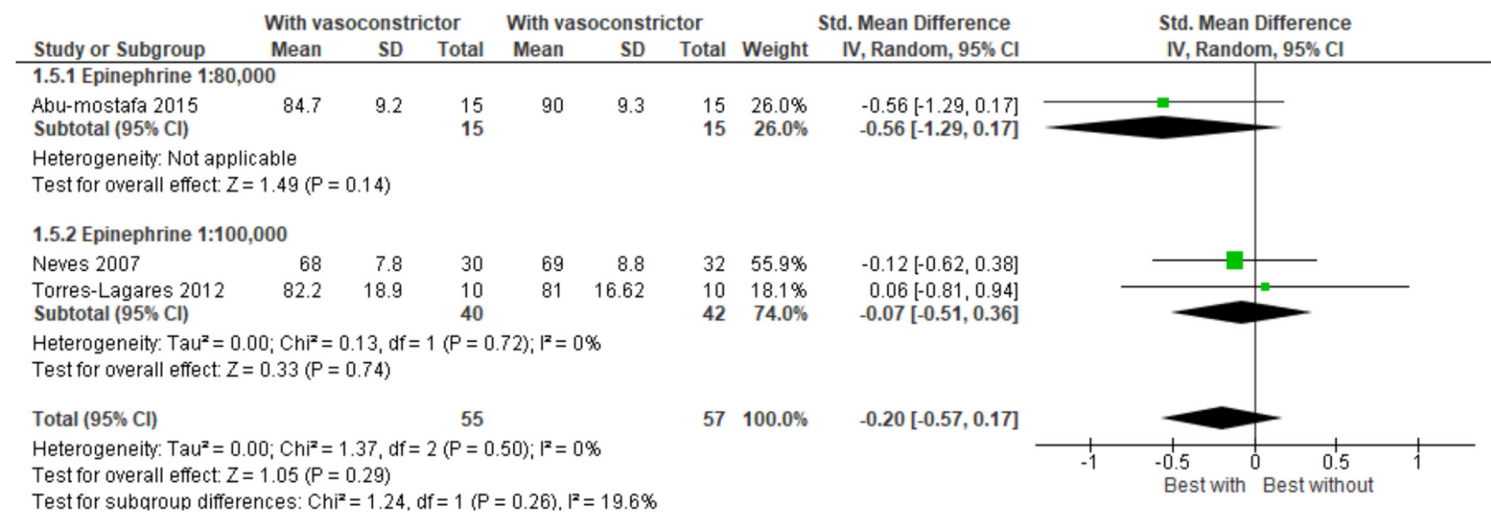

Figure 12 Heart rate associated with the use of anaesthetic with vasoconstrictor versus with the use of anaesthetic without vasoconstrictor, after the procedure period. 
blood pressure after dental procedures when compared with the use of LA without vasoconstrictor. Furthermore, the use of epinephrine (in low doses) does not alter the risk of arrhythmia, ST segment depression, mean arterial pressure, systolic and diastolic blood pressure and heart rate, suggesting safety in its use for these outcomes in adult patients with some types of CVD. However, the low quality of evidence demonstrates that literature needs further studies in order to confirm these results.

\section{Author affiliations}

${ }^{1}$ Faculdade São Leopoldo Mandic, Instituto de Pesquisas São Leopoldo Mandic, Campinas, Brazil

${ }^{2}$ Department of Pharmaceutical Sciences, Universidade de Sorocaba, Sorocaba, Brazil

${ }^{3}$ Division of Pharmacology, Anesthesiology and Therapeutics, Faculdade São Leopoldo Mandic, Instituto de Pesquisas São Leopoldo Mandic, Campinas, Brazil

\section{Twitter Luciane Cruz Lopes @lulopesbr}

Contributors CCG is the principal investigator and led the writing of the manuscript. LCL and RHLM are the project managers and co-investigators and contributed to the writing and revision of the manuscript. CCG, CCB, RHLM, JCR, JOA and NKA are co-investigators who contributed to screening the eligible studies and extracted the data of the studies, also participated the revision of the manuscript. MTS performed the statistical analysis, also participated the revision of the manuscript. All authors read and approved the final manuscript.

Funding The authors have not declared a specific grant for this research from any funding agency in the public, commercial or not-for-profit sectors.

Competing interests None declared.

Patient consent for publication Not required.

Provenance and peer review Not commissioned; externally peer reviewed.

Data availability statement Data are available on reasonable request. All data relevant to the study are included in the article or uploaded as supplementary information. However, other information is available on request.

Supplemental material This content has been supplied by the author(s). It has not been vetted by BMJ Publishing Group Limited (BMJ) and may not have been peer-reviewed. Any opinions or recommendations discussed are solely those of the author(s) and are not endorsed by BMJ. BMJ disclaims all liability and responsibility arising from any reliance placed on the content. Where the content includes any translated material, BMJ does not warrant the accuracy and reliability of the translations (including but not limited to local regulations, clinical guidelines, terminology, drug names and drug dosages), and is not responsible for any error and/or omissions arising from translation and adaptation or otherwise.

Open access This is an open access article distributed in accordance with the Creative Commons Attribution Non Commercial (CC BY-NC 4.0) license, which permits others to distribute, remix, adapt, build upon this work non-commercially, and license their derivative works on different terms, provided the original work is properly cited, appropriate credit is given, any changes made indicated, and the use is non-commercial. See: http://creativecommons.org/licenses/by-nc/4.0/.

\section{ORCID iDs}

Caio Chaves Guimaraes http://orcid.org/0000-0002-1672-528X

Luciane Cruz Lopes http://orcid.org/0000-0002-3684-3275

Cristiane de Cássia Bergamaschi http://orcid.org/0000-0002-6608-1806

Marcus Tolentino Silva http://orcid.org/0000-0002-7186-9075

Rogério Heládio Lopes Motta http://orcid.org/0000-0002-6983-7883

\section{REFERENCES}

1 World Health Organization. Cardiovascular diseases (CVDs), 2017. Available: http://www.who.int/mediacentre/factsheets/fs317/en/

2 Becker DE, Reed KL. Local anesthetics: review of pharmacological considerations. Anesth Prog 2012;59:90-102. quiz 2-3.

3 Jowett NI, Cabot LB. Patients with cardiac disease: considerations for the dental practitioner. Br Dent J 2000;189:297-302.
4 American Dental Association A. Guideline for teaching pain control and sedation to dentist and dental students 2012:1-18.

5 St George G, Morgan A, Meechan J, et al. Injectable local anaesthetic agents for dental anaesthesia. Cochrane Database Syst Rev 2018;7:Cd006487.

6 Haas DA. An update on local anesthetics in dentistry. $J$ Can Dent Assoc 2002;68:546-51.

7 Jage J. Circulatory effects of vasoconstrictors combined with local anesthetics. Anesth Pain Control Dent 1993;2:81-6.

8 Fencl JL. Guideline implementation: local anesthesia. AORN J 2015;101:682-92.

9 Kouba DJ, LoPiccolo MC, Alam M, et al. Guidelines for the use of local anesthesia in office-based dermatologic surgery. J Am Acad Dermatol 2016;74:1201-19.

10 Wadlund DL. Local anesthetic systemic toxicity. Aorn J 2017;106:367-77.

11 Brown RS. Local anesthetics. Dent Clin North Am 1994;38:963-4.

12 Bader JD, Bonito AJ, Shugars DA. A systematic review of cardiovascular effects of epinephrine on hypertensive dental patients. Oral Surg Oral Med Oral Pathol Oral Radiol Endod 2002;93:647-53.

13 Godzieba A, Smektała T, Jẹdrzejewski M, et al. Clinical assessment of the safe use local anaesthesia with vasoconstrictor agents in cardiovascular compromised patients: a systematic review. Med Sci Monit 2014;20:393-8.

14 Brand HS, Gortzak RA, Palmer-Bouva CC, et al. Cardiovascular and neuroendocrine responses during acute stress induced by different types of dental treatment. Int Dent J 1995;45:45-8.

15 Meyer FU. Haemodynamic changes under emotional stress following a minor surgical procedure under local anaesthesia. Int $J$ Oral Maxillofac Surg 1987;16:688-94.

16 New York Heart Association. Use of epinephrine in connection with procaine in dental procedures. J Am Med Assoc 1955;157:108.

17 Brown RS, Rhodus NL. Epinephrine and local anesthesia revisited. Oral Surg Oral Med Oral Pathol Oral Radiol Endod 2005;100:401-8.

18 Moher D, Liberati A, Tetzlaff J, et al. Preferred reporting items for systematic reviews and meta-analyses: the PRISMA statement. PLoS Med 2009;6:e1000097.

19 Altman R, Alarcón G, Appelrouth D, et al. The American College of rheumatology criteria for the classification and reporting of osteoarthritis of the hand. Arthritis Rheum 1990;33:1601-10.

20 Higgins JP, Green S. Cochrane Handbook for systematic reviews of interventions version 5.1.0. The Cochrane Collaboration, 2011.

21 Akl EA, Sun X, Busse JW, et al. Specific Instructions for estimating unclearly reported blinding status in randomized trials were reliable and valid. J Clin Epidemiol 2012;65:262-7.

22 Manning M, Stoev S, Chini B, et al. Peptide and non-peptide agonists and antagonists for the vasopressin and oxytocin V1a, V1b, V2 and OT receptors: research tools and potential therapeutic agents. Prog Brain Res 2008;170:473-512.

23 Higgins JPT, Thompson SG. Quantifying heterogeneity in a metaanalysis. Stat Med 2002;21:1539-58.

24 Guimaraes CC, Lopes Motta RH, Bergamaschi CdeC, et al. Local anaesthetics combined with vasoconstrictors in patients with cardiovascular disease undergoing dental procedures: systematic review and meta-analysis protocol. BMJ Open 2017;7:e014611.

25 Guyatt GH, Oxman AD, Kunz R, et al. GRADE guidelines: 7. Rating the quality of evidence--inconsistency. J Clin Epidemiol 2011;64:1294-302

26 Guyatt GH, Oxman AD, Santesso N, et al. GRADE guidelines: 12. preparing summary of findings tables-binary outcomes. J Clin Epidemiol 2013;66:158-72.

27 Guyatt GH, Thorlund K, Oxman AD, et al. GRADE guidelines: 13 . preparing summary of findings tables and evidence profilescontinuous outcomes. J Clin Epidemiol 2013;66:173-83.

28 Guyatt GH, Oxman AD, Montori V, et al. GRADE guidelines: 5 . Rating the quality of evidence--publication bias. J Clin Epidemiol 2011;64:1277-82.

29 Abu-Mostafa N, Aldawssary A, Assari A, et al. A prospective randomized clinical trial compared the effect of various types of local anesthetics cartridges on hypertensive patients during dental extraction. J Clin Exp Dent 2015;7:e84-8.

30 Bronzo ALA, Cardoso CG, Ortega KC, et al. Felypressin increases blood pressure during dental procedures in hypertensive patients. Arq Bras Cardiol 2012;99:724-31.

31 Cáceres MTF, Ludovice ACPP, Brito FSde, et al. Effect of local anesthetics with and without vasoconstrictor agent in patients with ventricular arrhythmias. Arq Bras Cardiol 2008;91:128-33.

32 Conrado VCLS, de Andrade J, de Angelis GAMC, et al. Cardiovascular effects of local anesthesia with vasoconstrictor 
during dental extraction in coronary patients. Arq Bras Cardiol 2007;88:507-13.

33 Davenport RE, Porcelli RJ, lacono VJ, et al. Effects of anesthetics containing epinephrine on catecholamine levels during periodontal surgery. J Periodontol 1990;61:553-8.

34 Laragnoit AB, Neves RS, Neves ILI, et al. Locoregional anesthesia for dental treatment in cardiac patients: a comparative study of $2 \%$ plain lidocaine and $2 \%$ lidocaine with epinephrine $(1: 100,000)$. Clinics 2009;64:177-82.

35 Neves RS, Neves ILI, Giorgi DMA, et al. Effects of epinephrine in local dental anesthesia in patients with coronary artery disease. Arq Bras Cardiol 2007;88:545-51.

36 Ogunlewe MO, James O, Ajuluchukwu JNA, et al. Evaluation of haemodynamic changes in hypertensive patients during tooth extraction under local anaesthesia. West Indian Med J 2011;60:91-5

37 Santos-Paul MAD, Neves ILI, Neves RS, et al. Local anesthesia with epinephrine is safe and effective for oral surgery in patients with type 2 diabetes mellitus and coronary disease: a prospective randomized study. Clinics 2015;70:185-9.

38 Torres-Lagares D, Serrera-Figallo María-Ángeles, Machuca-Portillo $\mathrm{G}$, et al. Cardiovascular effect of dental anesthesia with articaine ( $40 \mathrm{mg}$ with epinefrine $0,5 \mathrm{mg} \%$ and $40 \mathrm{mg}$ with epinefrine $1 \mathrm{mg} \%$ ) versus mepivacaine (30 $\mathrm{mg}$ and $20 \mathrm{mg}$ with epinefrine $1 \mathrm{mg} \%$ ) in medically compromised cardiac patients: a cross-over, randomized, single blinded study. Med Oral Patol Oral Cir Bucal 2012;17:e655-60.

39 Ribeiro ALP, Duncan BB, Brant LCC, et al. Cardiovascular health in Brazil: trends and perspectives. Circulation 2016;133:422-3. 